\title{
Novedades para la flora del Uruguay: nuevo registro de Agarista (Ericaceae)
}

\author{
Iván A. Grela ${ }^{1,2}$ y Carlos A. Brussa ${ }^{1}$
}

Recibido en 21/11/2003. Acepto en 07/12/2004

\begin{abstract}
RESUMO - (Novidades para a flora do Uruguai: novo registro de Agarista (Ericaceae)). A presença de Agarista chlorantha (Cham.) G. Don (Ericaceae) é mencionada pela primeira vez para a flora do Uruguai. Essa espécie arbustiva vive exclusivamente no extremo nordeste do país (Departamento de Rivera), nos topos e nas encostas das elevações conhecidas como "cerros chatos", formados por arenitos de idade jurássica. Nesse ambiente também crescem de forma quase exclusiva Agarista eucalyptoides (Cham. \& Schltdl.) D. Don, Ilex dumosa Reissek (Aquifoliaceae), Butia paraguayensis (Barb.-Rodr.) L.H. Bailey (Arecaceae) e Ocotea pulchella Mart. (Lauraceae), além de outras espécies arbóreas e arbustivas de distribuição mais ampla no país, em formações arbóreas abertas associadas a pastagens.
\end{abstract}

Palavras-chave: Agarista chlorantha, Ericaceae, flora do Uruguai

RESUMEN - (Novedades para la flora del Uruguay: nuevo registro de Agarista (Ericaceae)). Se reporta por primera vez la presencia de Agarista chlorantha (Cham.) G. Don (Ericaceae) para la flora del Uruguay. Esta especie arbustiva vive exclusivamente en el extremo noreste del país (Departamento de Rivera) en las cimas y laderas de las elevaciones conocidas como "cerros chatos" formados por areniscas de edad jurásica. En este ambiente también crecen en forma casi exclusiva Agarista eucalyptoides (Cham. \& Schltdl.) D. Don, Ilex dumosa Reissek (Aquifoliaceae), Butia paraguayensis (Barb.-Rodr.) L.H. Bailey (Arecaceae) у Ocotea pulchella Mart. (Lauraceae), además de otras especies arbóreas y arbustivas de más amplia distribución en el país, en formaciones arbóreas abiertas asociadas a pastizales.

Palabras clave: Agarista chlorantha, Ericaceae, flora del Uruguay

\section{Introducción}

El posicionamiento geográfico del Uruguay, así como la relativamente alta variabilidad en las características geológicas, geomorfológicas y topográficas permite que numerosas especies vegetales características de diferentes provincias fitogeográficas alcancen aquí sus límites de distribución natural.

Nuevos y más exhaustivos relevamientos florísticos realizados recientemente en algunas zonas que ofrecen ciertas peculiaridades geológicas y geomorfológicas han permitido detectar nuevas especies para la flora de este país, entre las cuales está la que se comunica en la presente nota.

En este caso se trata de relevamientos realizados en los "cerros chatos", denominados así por su peculiar cima aplanada (Chebataroff \& Zavala 1975). Constituyen elevaciones discretas de hasta 310 metros sobre el nivel del mar (msnm) formadas por la presencia de un estrato de areniscas jurasicas que han sufrido procesos de silicificación que lo hace más resistente a la erosión que afecta a las áreas circundantes.

Estas formaciones permiten la conexión florística con el sur de Brasil, Paraguay y el noroeste de Argentina, algunos de cuyos elementos penetran en el territorio uruguayo en esta zona de sedimentación jurásica, como por ejemplo Butia paraguayensis (Barb.-Rodr.) L.H. Bailey (Arecaceae), Agarista eucalyptoides (Cham. \& Schltdl.) D. Don (Ericaceae), Ilex dumosa Reissek (Aquifoliaceae), Ocotea pulchella Mart. y O. puberula (Rich.) Nees (Lauraceae), Campomanesia aurea O. Berg var. hatschbachii (Mattos) D. Legrand y Hexachlamys humilis O. Berg (Myrtaceae) además de otras especies herbáceas.

\section{Materiales y métodos}

Se recolectaron muestras de herbario en diferentes estados fenológicos en el Departamento de

\footnotetext{
1 Departamento Forestal, Facultad de Agronomía (Universidad de la República), Avda. E. Garzón 780, Cód. Post. 12.900, Montevideo, Uruguay

2 Autor para correspondencia: iagrela@adinet.com.uy
} 
Rivera, extremo noreste de Uruguay (Fig. 1), las que fueron estudiadas y determinadas en base a la bibliografía disponible (Judd 1995; Marques \& Klein 1975; Meissner 1863).

Las muestras fueron ingresadas al Herbario B. Rosengurtt de la Facultad de Agronomía de la Universidad de la República (MVFA).
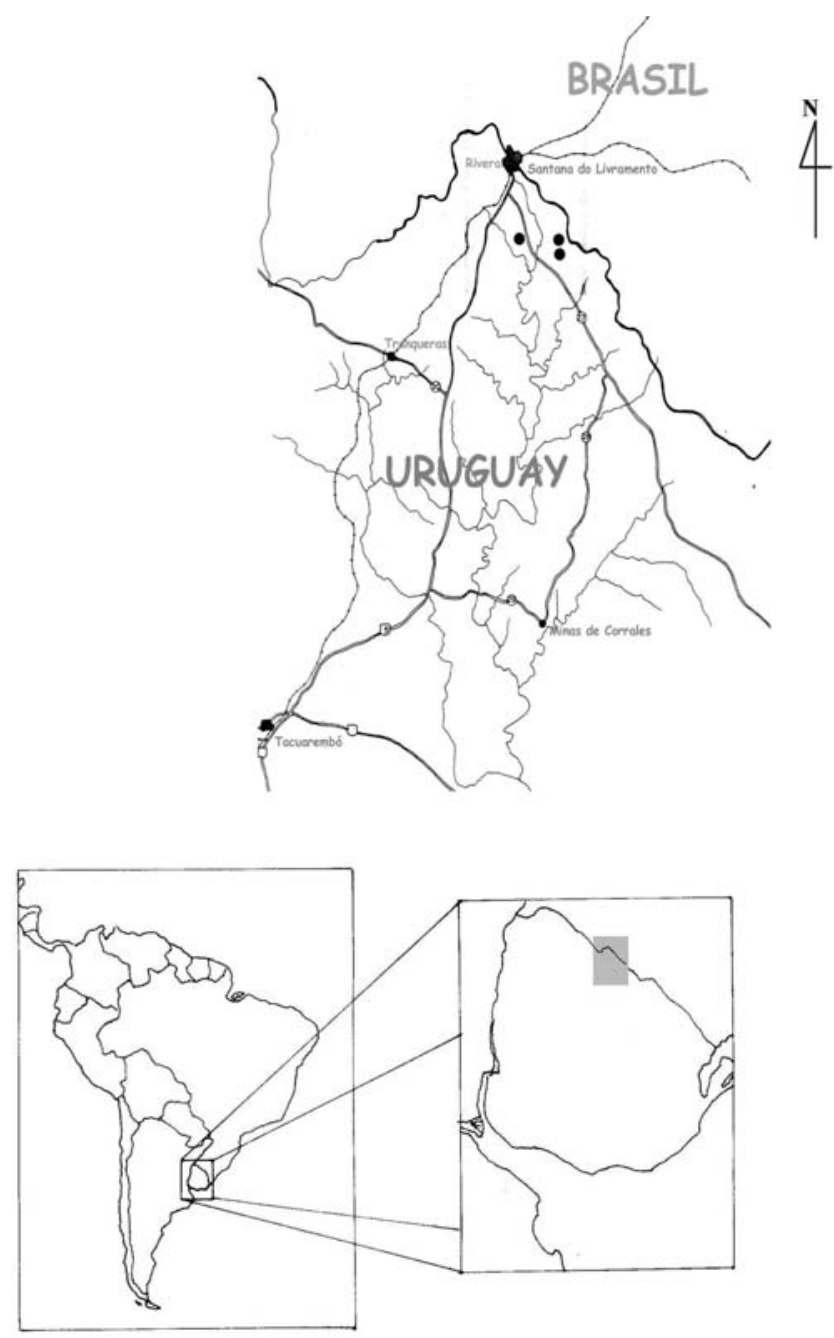

Figura 1. Localización de las colectas de Agarista chlorantha (Cham.) G. Don en Uruguay

\section{Resultados}

La familia Ericaceae Juss. está representada en la flora del Uruguay solamente por el género Agarista D. Don ex G. Don. Agarista eucalyptoides presenta un área de distribución muy restringida en el territorio uruguayo, limitándose exclusivamente al noroeste del Departamento de Rivera, muy cerca del límite con Brasil. Por su parte, Agarista chlorantha ocurre en los mismo tipos de ambientes, pero con un área más restringida aún que la especie anterior.
Clave para la diferenciación de las especies uruguayas de Agarista

1. Hojas adultas lanceoladas, glabras, lámina de 5-8 cm larg. $\times 2-3 \mathrm{~cm}$ ancho, pecíolos de 1-1,5 cm larg. Árboles A. eucalyptoides

1. Hojas adultas ovadas a suborbiculares, pelos glandulosos abundantes, lámina de $(0,8-) 1,5(-2,1) \mathrm{cm}$ larg. $\times(0,6-) 1,2(-1,6)$ cm ancho, pecíolo de $(0.1-) 0,2(-0.3) \mathrm{cm}$ larg. Arbustos A. chlorantha

Agarista chlorantha (Cham.) G. Don, Gen. Hist. 3: 838. 1934.

Andromeda chlorantha Cham., Linnaea 8: 508. 1833. Andromeda serrulata Cham., Linnaea 8: 506. 1833. Agarista serrulata (Cham.) G. Don, Gen. Hist. 3: 838. 1834.

Amechania subcanescens DC. Prodr. 7: 579. 1839. Leucothoe chlorantha (Cham.) DC., Prodr. 7: 604. 1839.

Leucothoe serrulata (Cham.) DC., Prodr. 7: 604. 1839. Leucothoe subcanescens (DC.) Meissn., in Martius, Fl. Brasil. 7: 163. t. 62, fig. 1. 1863.

Leucothoe chlorantha (Cham.) DC. var. subcanescens (DC.) Sleumer, Bot. Jahrb. Syst. 78: 454. 1959.

Fig. 2A-L.

Planta arbustiva de hasta 1,5-2 $\mathrm{m}$ alt., muy ramificada desde la base, ramas secundarias muy poco o no ramificadas, erguidas, cubiertas por abundante pilosidad, pelos simples, glandulosos y no glandulosos. Hojas apicales rojizas en la brotación. Hojas simples, de inserción espiralada, pecioladas. Lámina entera, de $(0,8-) 1,5(-2,1) \mathrm{cm}$ larg. $\times(0,6-) 1,2(-1,6) \mathrm{cm}$ ancho, mayoritariamente aplanada a veces levemente revoluta, desde suborbicular en la base de ramillas más viejas hasta ovadas (a veces elípticas) en los extremos de las mismas, levemente discoloras. Base cordada a amplia, ápice amplio y redondeado, a veces obtuso, apiculado, margen entero y algo revoluto en las hojas adultas, finamente aserrado en las hojas de brotes juveniles; ciliado, pelos glandulosos también presentes en el resto de la lámina, tanto en haz como envés. Pecíolo de $(0,1-) 0,2(-0,3) \mathrm{cm}$ larg., cubierto por abundantes pelos glandulosos. Inflorescencias en racimos axilares 6-10 floros, agrupadas hacia los extremos de las ramillas. Raquis de 15-20 mm larg., pedúnculos de 5-9 mm larg., densamente pubescentes, con 5-7 brácteas triangulares espiraladas, pedicelos 


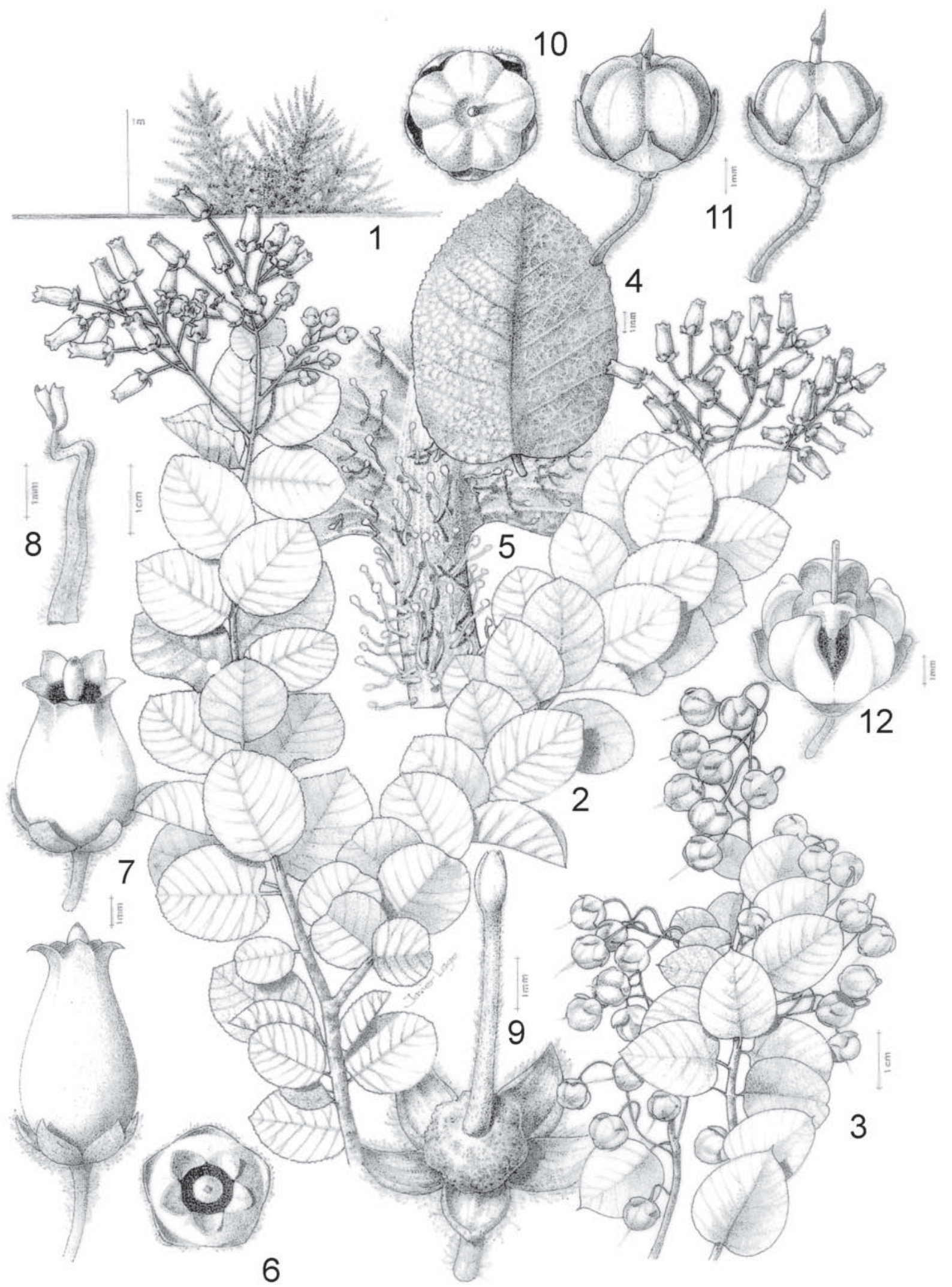

Figura 2. Agarista chlorantha (Cham.) G. Don. 1. Hábito. 2. Rama florífera. 3. Rama fructífera. 4. Hoja. 5. Pecíolo con pelos glandulosos. 6. Flor (vista frontal). 7. Flores (vista lateral). 8. Estambre. 9. Gineceo. 10. Fruto (vista frontal). 11. Frutos (vista lateral). 12. Fruto maduro abierto. (MVFA 29476, frutos; MVFA 29779, flores y hojas). 
laxos y curvos hacia abajo, de 5-7 mm larg., pubescentes, con 2 bracteolas linear- triangulares, castañas en la base y articulados inmediatamente debajo del receptáculo. Las dimensiones corresponden al momento de la antesis ya que posteriormente continúan su crecimiento. Flores actinomorfas, hermafroditas, cáliz formado por 5 sépalos libres, triangulares, $15 \mathrm{~mm}$ ancho en la base $\times 2 \mathrm{~mm}$ larg., pubescentes con pelos glandulosos en la cara abaxial. Corola gamopétala, tubulosa, levemente urceoleada, de 3-5 $\mathrm{mm}$ ancho en la base $\times 7-9 \mathrm{~mm}$ larg., limbo pentalobado, angosto, formado por 5 lobos triangulares de 1-1,5 mm larg., glabra, de color blanco crema, a veces con el borde de los lobos de color rojizo, caduca. Androceo formado por 10 estambres libres, filamentos achatados, con abundante pubescencia de pelos no glandulosos. Cápsula globosa a esférica de 3-3,5 mm alt. × 5-6 mm diám. al madurar, dehiscencia loculicida. Cáliz persistente y acrecido, cubriendo hasta la mitad de la cápsula. En la maduración de los frutos el raquis alcanza los 5-7 cm, los pedúnculos 1-1,5 cm y los pedicelos 0,9-1,2 cm larg. Fecha de floración: desde fines de agosto hasta fines de octubre. Fecha de fructificación: desde noviembre a febrero.

Material examinado: URUGUAY. Rivera: Paso Serpa: 3/I/2001, fr., Brussa \& Grela s.n. (MVFA 29476); 31 ${ }^{\circ} 00^{\prime}$ S 55 32' W, 30/VIII/2001, fl., Brussa \& Grela s.n. (MVFA 29684); 31 $01^{\circ}$ ' S $55^{\circ} 27^{\prime} \mathrm{W}$, 15/X/2001, fl., Brussa et al. s.n. (MVFA 29793); 15/X/2001, fl., Brussa et al. s.n. (MVFA 29779); 30/X/2002, fl., Grela s.n. (MVFA 32738).

\section{Discusión}

Judd (1995) reporta Agarista chlorantha exclusivamente para el sureste de Brasil, desde el Distrito Federal, sur de Minas Gerais y São Paulo, hasta Paraná y Santa Catarina donde parece ser más abundante, y A. eucalyptoides con un área similar, aunque incluyendo Rio Grande do Sul y el noreste de Uruguay. Por lo tanto, este nuevo registro amplía el área de distribución de la primera de las especies mencionadas, siendo la localización más austral registrada hasta el presente.

Agarista chlorantha presenta un área muy reducida en Uruguay, limitándose a las laderas de algunos cerros de arenisca del noroeste del Departamento de Rivera (Fig. 1), ambiente que comparte con Agarista eucalyptoides, aunque obviamente es probable que dicha área puede verse ampliada a partir de nuevos relevamientos florísticos en esta zona. Estos cerros de areniscas jurasicas y cretácicas suelen presentar varios estratos que albergan en forma exclusiva o casi exclusiva varias especies herbáceas, arbustivas y arbóreas. La vegetación se caracteriza por una cobertura arbórea y arbustiva relativamente escasa restringida a las laderas y cimas de dichos cerros, y un componente florístico en el que se destaca un número importante de especies exclusivas o casi exclusivas tales como las mencionadas en la introducción.

El hallazgo de Agarista chlorantha en Uruguay resulta significativo no solamente desde el punto de vista florístico, sino fitogeográfico, ya que contribuye a reforzar la idea de que la flora del norte Uruguay está vinculada más estrechamente a la flora del sur de Brasil que a la de las "pampas" del centro de Argentina (Chebataroff 1942).

\section{Agradecimientos}

A Javier Lage, por las ilustraciones; a la Compañía Forestal del Uruguay S.A. (COFUSA), por financiar los estudios de campo; a los dos revisores anónimos y a la Editoría, por sus comentarios y sugerencias.

\section{Referencias bibliográficas}

Chebataroff, J. 1942. La vegetación del Uruguay y sus relaciones fitogeográficas con el resto de América del Sur. Revista del Instituto Panamericano de Geografía e Historia: 49-90.

Chebataroff, J. \& Zavala, M.E. 1975. Relieve del Uruguay. Revista Uruguaya de Geografía. Segunda Serie (3): 2-47.

Judd, W.S. 1995. Agarista. Pp. 295-344. In: J.L. Luteyn (ed.). Ericaceae Part II. The superior-ovaried Genera. Flora Neotropica, Monograph n. 66. New York, The New York Botanical Garden.

Marques, M. \& Klein, R. 1975. Ericáceas. In: R. Reitz (ed.). Flora Ilustrada Catarinense, pt. 1 ERIC. Itajaí, Herbario Barbosa Rodríguez.

Meissner, C.F. 1863. Ericaceae. Pp. 119-174. In: C.F.P. Martius (ed.). Flora Brasiliensis VII. 